\title{
UNA BULA INCUNABLE DESCONOCIDA EN EL INSTITUTO VALENCIA DE DON JUAN. NUEVOS DATOS DE LA IMPRENTA SALMANTINA ${ }^{1}$
}

\author{
Fermín de los Reyes Gómez* \\ Facultad de Ciencias de la Documentación. Universidad Complutense de Madrid. \\ José Luis Gonzalo Sánchez-Molero** \\ Facultad de Ciencias de la Documentación. Universidad Complutense de Madrid. \\ Ana Belén Sánchez Prieto*** \\ Facultad de Ciencias de la Documentación. Universidad Complutense de Madrid.
}

\begin{abstract}
Resumen: El hallazgo de una bula de Cruzada incunable desconocida en el Instituto Valencia de Don Juan, adquirida por la condesa de Oropesa, da pie al estudio de su procedencia y a su análisis e identificación. La bula fue impresa en las prensas salmantinas de Juan de Porras y Juan de Montejo, pero los datos de la documentación conservada en diversos archivos, lleva a la revisión de la historia de la imprenta incunable de Salamanca, tan compleja como enigmática, ante la posible existencia de, al menos, otro taller en la ciudad a cargo de Juan de San Vicente y Rodrigo de Escobar.

Palabras clave: Bula; incunable; imprenta; Salamanca; Valencia de Don Juan; condesa de Oropesa; Juan de Porras; Juan de Montejo; Juan de San Vicente; Rodrigo de Escobar.

Title: AN UNKNOWN INCUNABULAR BULL IN THE INSTITUTO VALENCIA DE DON JUAN. NEW INFORMATION ABOUT THE EARLY PRINTING PRESS IN SALAMANCA.

Abstract: The discovery in the Instituto Valencia de don Juan of an until now unknown incunabular bull of crusade acquired by the Countess of Oropesa, is a good opportunity to study its provenance and identification. This bull was printed in Salamanca in the offices of Juan de Porras and Juan de Montejo, but some pieces of information retrieved in several Spanish archives have allowed the authors to reconsider the history of the printing presses in Salamanca, as intricate as enigmatic, since there are some clues that point to the presence in the same place and time of at least other two workshops, those of Juan de San Vicente and Rodrigo de Escobar.

Keywords: Bull; incunabula; printingpress; Salamanca; Valencia de Don Juan; Countess of Oropesa; Juan de Porras; Juan de Montejo; Juan de San Vicente; Rodrigo de Escobar.
\end{abstract}

Copyright: (C) 2017 Servicio de Publicaciones de la Universidad de Murcia (Spain). Este es un artículo de acceso abierto distribuido bajo los términos de la licencia Creative Commons Reconocimiento 4.0 Internacional (CC BY $4.0)$.

\section{INTRODUCCIÓN}

La historia de los orígenes de la imprenta en España se va realizando a partir de hallazgos de ejemplares de ediciones desconocidas y, en menor medida, de documentos sobre impresiones o sus protagonistas. Son los impresos menores los que más sorpresas nos pueden deparar, entre los que destacan las bulas de indulgencias al ser un producto temprano elaborado por múltiples talleres españoles. Recuérdese la Bula de Rodrigo de Borja, de temprana (1473) y desconocida impresión (Reyes Gómez, 2008), paralela a las tres bulas para la fábrica de la catedral de Sevilla, una de 1 de mayo y las otras dos de septiembre de 1473, hoy en paradero desconocido (Hazañas y La Rúa, 1892, p. 5-6).

En este artículo se da noticia de una edición incunable desconocida hallada en el Instituto Valencia de Don Juan, documento que aporta nuevos datos de las tempranas prensas salmantinas y que plantea dudas acerca de la impresión de bulas de Cruzada.

\footnotetext{
*freyes@pdi.ucm.es

***ilgonz01@pdi.ucm.es

*** anabelen.sanchez.prieto@pdi.ucm.es
}

Recibido: 10-01-2017; 2 $2^{\mathrm{a}}$ versión: 03-10-2017; aceptado: 06-10-2017.

DE LOS REYES GÓMEZ, F., GONZALO SÁNCHEZ-MOLERO, J.L. y SÁNCHEZ PRIETO, A.B. Una bula incunable desconocida en el Instituto Valencia de Don Juan. Nuevos datos de la imprenta salmantina. Anales de Documentación, 2017, vol. 20, nº 2. Disponible en: http://dx.doi.org/10.6018/analesdoc.20.2.279801. 


\section{LAS BULAS Y SU CONTROL BIBLIOGRÁFICO}

De las bulas de indulgencias se realizaron cientos de ediciones con fines diversos, como la Cruzada, guerra de Granada, financiación de catedrales, monasterios, órdenes religiosas, hospitales, iglesias, etc. Su carácter de documentos personales propició su desaparición una vez que cumplieron su objetivo o acabaron incorporándose a archivos de dispar destino cuando no acompañaron a los difuntos en su último viaje.

Pese a los cientos de miles de ejemplares impresos, se conservan apenas 200. Se agudiza la falta con la dispersión de las noticias y la dificultad para su identificación. Así, el Incunabula Sorth Title Catalogue (ISTC), gestionado por la British Library, recoge 80 bulas españolas, mientras que nuestro Catálogo Colectivo del Patrimonio Bibliográfico Español (CCPBE) 60. Es cierto que hay una decena de la que tan solo se conoce noticia a través de documentos. Sin embargo, el trabajo de búsqueda y control de las bulas incunables españolas lleva a disponer de 121 noticias, lo que incrementa de forma sustancial su número, que irá aumentando. Se han dado recientes noticias de 7 ediciones hasta ahora desconocidas (Reyes, 2014 y 2016; Boscá-Mandingorra, 2015), y esperamos que sigan publicándose más.

La variedad de finalidades y de organismos editores llevó a su impresión en talleres repartidos por toda España y en prácticamente todo el recorrido temporal de la imprenta. Así, y por orden alfabético, se publican, al menos que se conozca, en Barcelona, Burgos, Lérida, Montserrat, Orense, Pamplona, Salamanca, Sevilla, Toledo, Valencia, Valladolid, Valldemosa, Zamora y Zaragoza. Aparte están los desconocidos lugares de impresión de la Bula de Borja y de otras aún sin identificar. Su dispersión es notable, si bien hay unas importantes colecciones en la Biblioteca de Cataluña (Barcelona), Museo de Segovia, Catedral de Segovia, Biblioteca Nacional de Francia; o en el Archivo Histórico Nacional.

\section{DOCUMENTACIÓN DEL INSTITUTO VALENCIA DE DON JUAN}

La búsqueda de documentación en el archivo y biblioteca del madrileño Instituto Valencia de Don Juan (IVDJ) ha deparado el hallazgo de diversas bulas en el Envío 127 (Privilegios. Bulas y Documentos varios). Dos de ellas son manuscritas y en pergamino, adquiridas por Leonor de Zúñiga: una con fecha de 30 de enero de 1467, y otra, la más significativa, expedida por el cardenal Rodrigo de Borja el 26 de noviembre de 1473. De las otras dos, adquiridas por la Condesa de Oropesa a fines del siglo xv, vamos a describir la más antigua e importante.

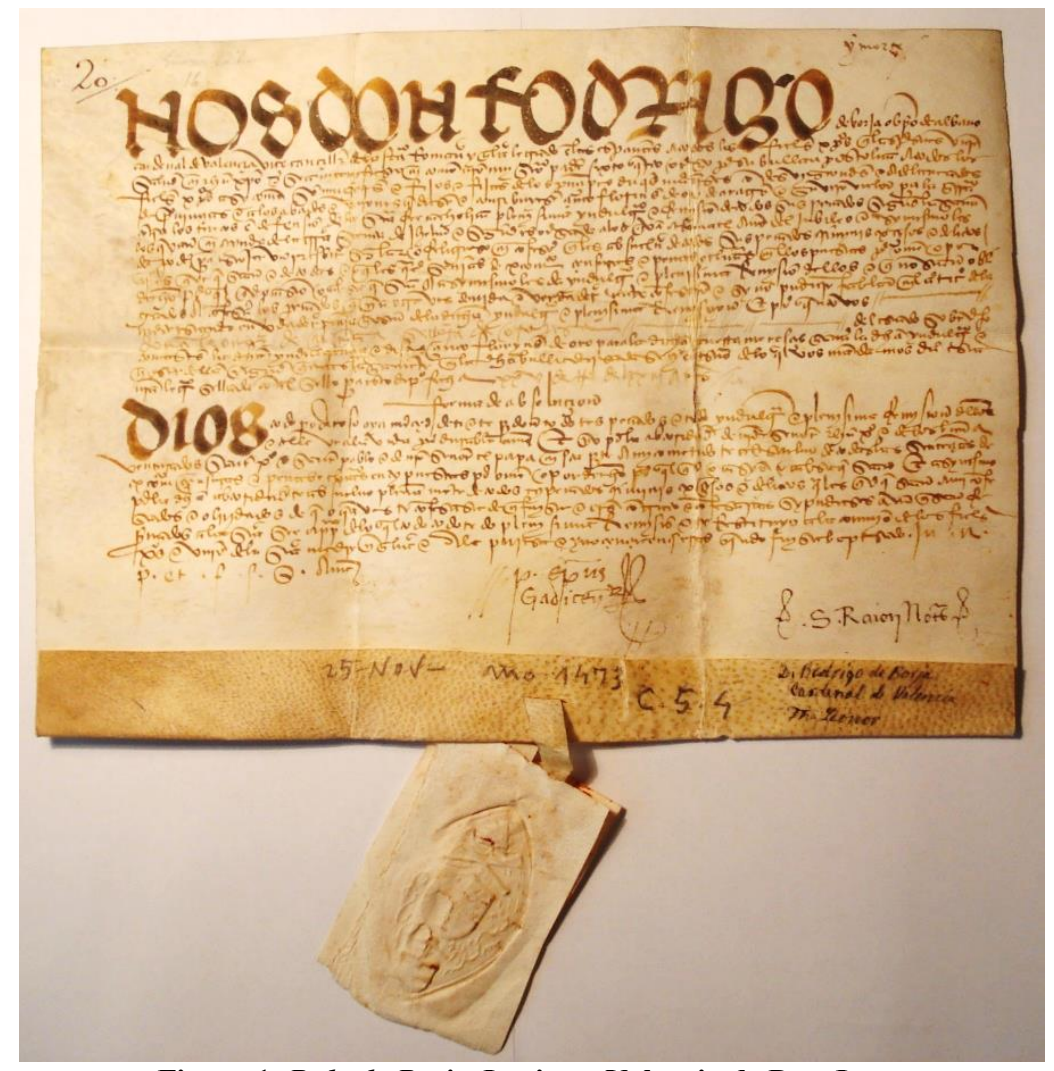

Figura 1. Bula de Borja. Instituto Valencia de Don Juan. 
Ninguna de estas bulas incunables ha sido recogida hasta ahora en catálogos, a pesar de ser incluidas en 1913 en el Inventario topográfico que Antonio Paz y Mélia redactó entonces. Sin embargo, el uso interno de este Inventario, manuscrito en su mayor parte, explica que su existencia haya permanecido oculta para los incunabulistas durante más de un siglo. Esto resulta especialmente paradójico, pues las de Valencia de Don Juan están estrechamente relacionadas con otras bulas incunables, bien conocidas desde tiempo atrás, como la conocida Bula de Guinea (c. 1477-1480) y otras que fueron adquiridas precisamente por Leonor de Zúñiga, como la Bula para la Iglesia de San Salvador de Ávila (1481) y la Bula para la Guerra de Granada (c. 1484). Que todas ellas, a pesar de su actual dispersión, fueran adquiridas por la misma persona a fines del cuatrocientos evidencia que procedían de una misma colección documental, fragmentada a fines del siglo xix. Sin embargo, solo una parte de aquellas bulas incunables mereció la atención de los especialistas de la época (Konrad Haebler, James P. R. Lyell), mientras que la otra, adquirida por los Condes de Valencia de Don Juan, quedó en el olvido.

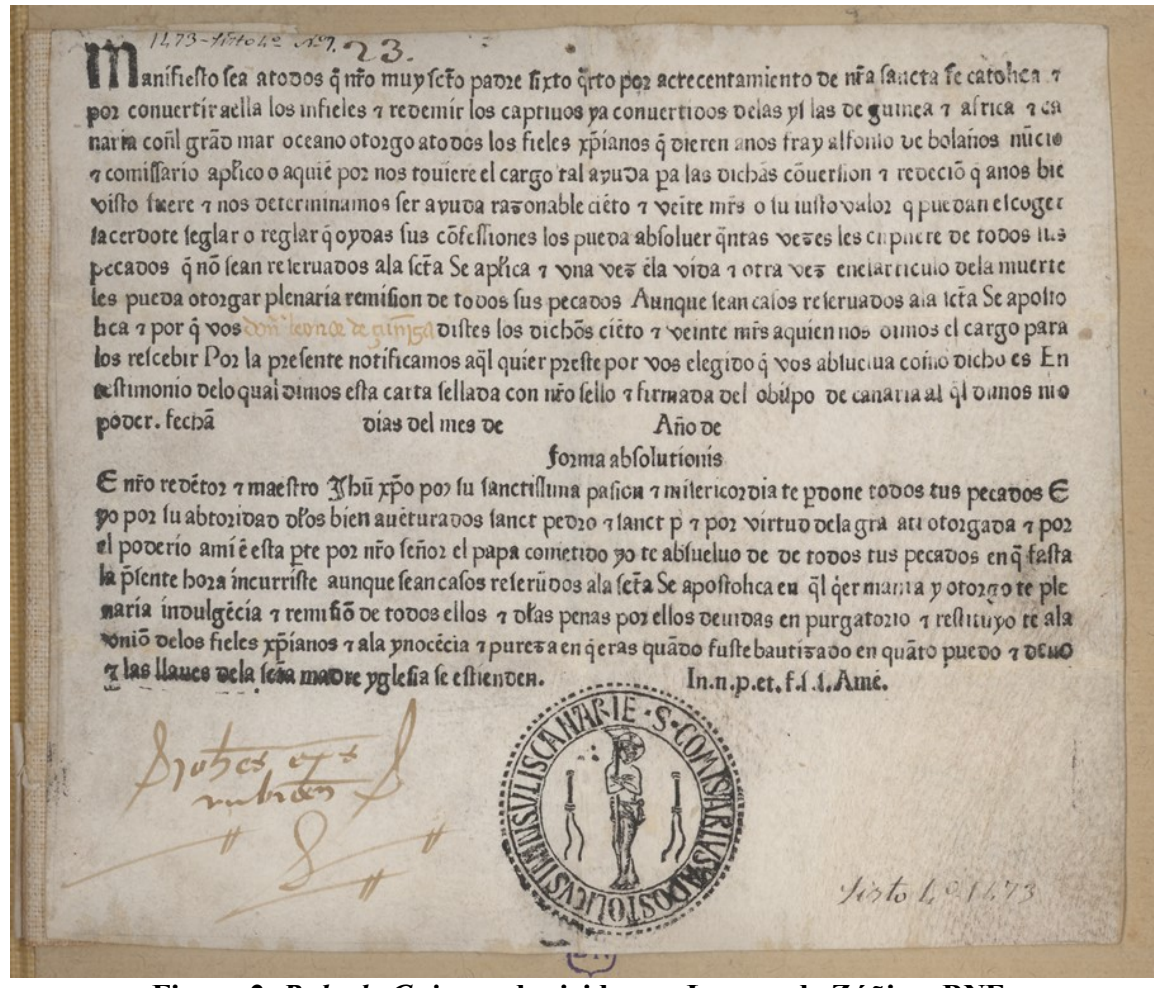

Figura 2. Bula de Guinea adquirida por Leonor de Zúñiga. BNE.

Para comprender la presencia de esta colección de bulas bajomedievales en el IVDJ se hace necesario recordar cómo y cuándo se creó este centro de investigación y museo madrileño ${ }^{2}$. Fue fundado en 1916 por Guillermo de Osma (1853-1922), político y notable intelectual español, además de gran coleccionista de antigüedades, documentos y libros. Casado en 1888 con Adela Crooke, condesa de Valencia de Don Juan, tuvo una brillante trayectoria diplomática y política. En 1895 fue nombrado secretario del Ministerio de Ultramar del último gobierno de Cánovas, y en la primera etapa de Silvela recibió el nombramiento de subsecretario de Hacienda. Dos veces ministro de Hacienda con Maura, entre 1896 y 1919 fue diputado a Cortes por el Partido Conservador. En febrero de 1908 abandonó la carrera política argumentando motivos de salud, pero siguió como consejero de Estado. En adelante se dedicó al coleccionismo y al estudio del arte, incrementando la colección familiar ubicada en su palacete de la calle Fortuny, en Madrid.

Osma realizó las adquisiciones con el único objetivo de crear un corpus que sirviera para la investigación del Arte y de la Historia de España. Fiel a este principio, el 15 de marzo de 1916 decidió crear junto a su mujer un instituto que impidiera la fragmentación de su colección (el matrimonio no tuvo descendencia) y que funcionara como un centro dedicado al estudio de las colecciones artísticas, arqueológicas, documentales y numismáticas que ambos habían reunido o heredado de los anteriores condes ${ }^{3}$. Resumió las funciones del Instituto en tres objetivos: garantizar la conservación y la unidad de la colección; catalogar, describir e indizar las piezas artísticas y los documentos adquiridos; y publicar investigaciones y guías sobre su patrimonio. Como se dice en el propio documento fundacional:

“[...] en orden de prelación, en cada tiempo, han de inscribirse los tres conceptos de la misión de nuestro Instituto: $1^{\circ}$ Antes y siempre, conservar; $2^{\circ}$ enseguida, y por ser más urgente, inventariar: en Índices que á su 
vez sean base de los Catálogos en que ya se actúe en términos de su publicación; y $3^{\circ}$ publicar, además, cuanto trascienda á servicio activo del interés público que se compendie en cultura y conocimiento de las Artes industriales y de la Historia patria",4.

Puede sorprender que entre las principales funciones del Instituto se estableciera la de inventariar sus fondos, y que se le añadiera la fórmula "por ser más urgente", pero lo cierto es que la enorme colección privada reunida por los condes se había ido configurando sin el apoyo de un registro y catálogo de las piezas que iban siendo adquiridas. Quizá esto pareciera menos grave cuando se trataba de grandes obras que eran exhibidas en el museo del palacete, pero resultaba especialmente difícil localizar y estudiar piezas artísticas más pequeñas, como libros y documentos. Además, una gran parte de este fondo documental no había sido reunido por Guillermo de Osma, sino por los padres de su esposa: Juan Crooke y Adela Guzmán, condes de Valencia de Don Juan, especialmente por el primero. Fallecido este en 1904, su testimonio oral sobre la procedencia de muchas piezas había sido durante mucho tiempo la única fuente de acceso a las mismas.

Juan Crooke y Navarrot (1829-1904) fue el fundador del proyecto cultural que en 1916 acabaría convirtiéndose en el Instituto. En su juventud había sido secretario de la embajada española en París, donde conoció los esfuerzos por la recuperación del patrimonio de Francia, tan dañado desde la Revolución y las Guerras Napoleónicas. Cuando regresó a España, y gracias a su matrimonio en 1855 con Adela Guzmán, XXIII condesa de Valencia de Don Juan, tuvo acceso a una importante fortuna, lo que le permitió salvar de su destrucción, o venta al extranjero, piezas de la cultura española. Al llegar al trono Alfonso XII fue nombrado director de la Armería Real, realizándose durante su mandato su catálogo (1898). También estudió los tapices de la colección real, publicando en 1903 un amplio catálogo. Estas obras le proporcionaron una merecida fama como erudito, siendo elegido en 1902 como Académico de la de Historia. $\mathrm{Su}$ intervención más famosa en la salvaguarda del patrimonio nacional fue la compra del archivo de la Casa de Altamira, puesto a la venta como papel viejo en $1870^{5}$, razón de que el Instituto cuente con un valioso archivo, muy consultado por los historiadores interesados en el reinado de Felipe II o sobre la nobleza española durante los siglos modernos.

Al fallecer Juan Crooke se carecía de un inventario completo de la colección, por lo que a fines de 1911 Osma encomendó al archivero Antonio Paz (Gómez Díaz, 2001-2002) que lo redactara, siendo meticulosamente realizado por este entre enero de 1912 y febrero de 1915. Paz revisó los "envíos" de papeles (nombre que el conde dio a los legajos) y redactó un Inventario en dos volúmenes, manuscrito y mecanografiado a partes, al que se añadió después un tercero de adendas. Aunque este proceso permitió poner orden en la documentación, otro de los propósitos que tuvo esta catalogación fue localizar información sobre el secretario Mateo Vázquez, de quien Osma deseaba escribir una biografía. No en vano, en 1916, Paz terminada ya su catalogación, remitió al conde una lista de documentos importantes sobre el secretario que había hallado entre los papeles de la Casa de Altamira ${ }^{6}$.

Así fue cómo en 1913 Paz se encontró con un insospechado conjunto de bulas bajomedievales en el Envío 127, que etiquetó bajo la denominación "Privilegios. Bulas y Documentos varios (1439, 1467-1512)". Los papeles que contenía esta caja fueron revisados entre el 5 y el 16 de octubre de dicho año, y el archivero señaló entonces que en su interior se hallaban las siguientes bulas (f. 454r): «Por las circunstancias siguientes son curiosas 4 Bulas, dos a favor de $D^{a}$ Leonor de Zúñiga, y dos a favor de
la Condesa de Oropesa.

La $1^{a}$ manuscrita en vitela (30 de enero de 1467) tiene sello de placa ovalado pendiente con la imagen de $S$. Marcial.

La $2^{a}$ expedida por D. Rodrigo de Borja, Cardenal de Valencia, (26-nov.1473) está en vitela, y tiene sello de placa pendiente, con las armas del Cardenal [a lápiz añade Guillermo de Osma, con evidente interés: "Incunable?]

Las otras dos, en papel (148* y 1493) son de Composición, por haber dado la Condesa 500 mrs. para la Guerra de Granada. (Incunables)

Otra de Cruzada a favor de la misma Condesa, está impresa en pergamino en 1490, y por tanto, es incunable... [y a lápiz de nuevo añade Osma con nerviosismo una llamada de atención en lápiz rojo: “/”»]"

Dos de las bulas impresas permanecen hoy en el mismo lugar, pero ya no está la tercera, fechada en 1490. La bula borjiana manuscrita pasó a otro lugar, pues parte de los documentos del Envío 127 fueron extraídos para formar una colección aparte del archivo y biblioteca del Instituto, la de documentos medievales, creada a finales de los años 80 del siglo pasado por Gregorio de Andrés ${ }^{8}$. 
¿Cómo llegaron estas bulas al Instituto Valencia de Don Juan? No ayuda a resolver esta cuestión el llamado "Libro negro de adquisiciones" (por sus tapas negras), en el que se apuntaron las sucesivas compras, donaciones y algunas restauraciones de materiales, dado que contiene principalmente las compras que se realizaron desde mayo de 1922 hasta 1959, estando las bulas en sus colecciones desde algunos años atrás. Así, el único dato cierto es que en febrero de 1913 Paz y Mélia catalogó el contenido del citado Envío 127. Contenía documentos de los siglos xv y xvi, relacionados en gran parte con los condes de Oropesa y los duques de Frías. Tal procedencia parecía desmentir que su contenido proviniera de los fondos del archivo de los condes de Altamira, adquiridos hacia 1870. Esto ya lo advirtió el propio Paz, quien al inicio de su Inventario topográfico indicó en una nota introductoria sobre su composición (de 31 de marzo de 1915), que casi todos los envíos procedían probablemente del archivo de los condes de Altamira, excepto algunos, entre los cuales incluyó precisamente el Envío 127. No así otros cercanos, como los numerados del 121 al 124, o el 128. Lo que no aclara Paz es de dónde venía dicha documentación. En todo caso, esta nota da a entender que si nada dice es porque en realidad nada sabía. El proceder habitual, tanto del archivero como del conde, era el de anotar el origen, no tanto de los envíos (pues recordemos que casi todos provenían del archivo de la Casa de Altamira), como sí de otros fondos allegados después de 1915. Nos referimos a los denominados como envíos adicionados, o adiciones, que se añadieron en un nuevo tomo del catálogo topográfico a partir de este año. En ellos Osma anota casi siempre el nombre del librero a quien se compró el material, o el año aproximado desde que se encontraba en sus manos un papel adicionado, o quién y cuándo donó alguna documentación. Del Envío 127 nada se dice y el propio proceder de Osma al revisar su inventario, mostrando curiosidad y extrañeza por los textos incunables presentes en el mismo, indica que los documentos no habían sido comprados por él.

Todo parece indicar que quien compró esta colección documental fue su suegro, Juan Crooke, mucho más interesado en allegar documentación nobiliaria medieval y moderna, como la compra de lotes de los archivos de las Casas de Altamira y Velada revelan. Mas, ¿por qué estaban tan seguros en 1915 de que su origen no estaba en la colección Altamira? Sin duda, lo consideraron así guiándose por lo "exógeno" de su contenido y por la historia genealógica que manifiesta. Paz, que conocía muy bien otros archivos nobiliarios (casas ducales de Alba y de Medinaceli), sabía que la Casa de Oropesa estaba ligada a los duques de Frías, y no a los condes de Altamira. Tras ordenar más de cien cajas con papeles antiguos en poder de los Condes de Valencia de Don Juan, era evidente que aquel Envío 127 difería de los anteriores. Para corroborar su percepción basta con observar que el Envío contenía no menos de cinco documentos que tenían relación con doña Leonor de Zúñiga y con la condesa de Oropesa, así como otros muchos relativos a su marido e hijo. El primer papel, manuscrito, por ejemplo, es una licencia otorgada por el obispo de Ávila, Alfonso de Fonseca, a Leonor de Zúñiga en 1473, autorizándola a pedir limosnas en la vicaría de Oropesa para reparar la ermita de Nuestra Señora de Peñuelas.

El contenido del Envío 127 hace evidente que la documentación (y las bulas) solo pueden proceder del antiguo archivo de la casa ducal de Frías, a la que se incorporaría el condado de Oropesa en 1802. Los papeles catalogados por Paz son de tal relevancia que no se entiende que, por mucho parentesco o vecindad que se tuviera con los marqueses de Velada, los condes de Oropesa y los duques de Frías les transmitieran algunos documentos privativos. La lista de los mismos se inicia precisamente con un privilegio de Juan II a Pero Fernández de Velasco otorgándole el señorío sobre Soba, Ruerga, Puebla de Arganzón y San Sadornín (1439). Hallamos también en el Envío 127 una licencia del rey Fernando el Católico al Condestable de Castilla para que pudiera hacer mayorazgo en cabeza de su hija Juliana Ángela de Aragón (1510), e incluso podemos encontrar el título original de Condestable de Castilla otorgado a Íñigo de Velasco, duque de Frías, en 1512. Es imposible pensar que papeles de tanta importancia pasaran a los marqueses de Velada, quienes, además, no tenían entonces entronque directo con la Casa de Frías.

Se observa, además, la existencia de curiosos paralelismos entre documentos del Archivo Histórico NacionalNobleza (Frías) y del Instituto Valencia de Don Juan ${ }^{9}$. Así, por ejemplo, en el Envío 127 todavía se conserva la cédula de Fernando el Católico a sus contadores para que asentasen en sus libros que el oficio de traer el estoque real había sido concedido al conde de Oropesa (1504). Pues bien, en el legajo 535, $\mathrm{n}^{\circ} 1$ de Frías (AHN-Nobleza) se encuentra abundante documentación sobre los derechos de la casa de Oropesa a llevar el real estoque entre 1420 y 1851 . Pero nuestras sospechas se tornan en evidencias cuando se constata que del citado título de Condestable, otorgado en 1512, encontramos que actualmente solo existe en el Archivo de la Nobleza un mero traslado ${ }^{10}$. Asimismo, y como el condado de Fuensalida también se incorporó a la casa de Frías, no ha de sorprender que Paz catalogara en 1915, en aquel Envío 127, una cédula, original y con su sello de placa, otorgada por Enrique IV, apartando el lugar de Fuensalida de la jurisdicción de la ciudad de Toledo (1470). Y de nuevo, en la sección Nobleza del AHN observamos que no se conserva el documento original, sino cuatro copias autorizadas (Leg. $249, \mathrm{n}^{\text {o }} 4$ y 5$)^{11}$. Lo mismo acontece con el privilegio antes citado del rey Juan II otorgando el señorío de Soba, Ruerga, Puebla de Arganzón y San Sadornín (1439); en el AHN solo podemos encontrar una copia del mismo, fechada en Medina de Pomar, el 19 
septiembre de 1530, y catalogada casi con las mismas palabras que empleara Paz en 1915, quizás porque ambos documentos iban acompañados del mismo regesto en su archivo nobiliario original ${ }^{12}$.

Así pues, se abre paso una hipótesis más verosímil, la de que estos papeles fueron vendidos, extrayéndose de legajos del archivo nobiliario de Frías. Las bulas compradas por Leonor de Zúñiga y por la condesa de Oropesa debieron de mantenerse en el archivo de los Duques de Frías hasta fines del siglo xix. El condado de Oropesa ya se había integrado en la Casa ducal desde principios de la centuria, tras fallecer en 1802, sin sucesión directa, María Teresa de Silva Álvarez de Toledo (1762-1802), XIV condesa de Oropesa. El condado de Oropesa pasaría, con sus títulos anexos, a Diego Antonio Fernández de Velasco López Pacheco (1754-1811), XIII duque de Frías. Durante el siglo xix hubo dos ocasiones en las que el archivo de la Casa pudo sufrir ventas o mermas. Una fue en 1861, al fallecer Bernardino Fernández de Velasco Pacheco Téllez-Girón, XIV duque de Frías y XIV de Escalona y XVII conde de Oropesa (1783-1861), cuyo primogénito, José María Bernardino Silverio Fernández de Velasco (1836-1888), heredó el ducado de Frías, y su hermana Bernardina Fernández de Velasco Pacheco Téllez-Girón (1815-1869), el ducado de Escalona. El otro momento, tras fallecer, en 1888, José Ma Bernardino, XV duque de Frías, que llevó a su viuda y herederos a liquidar parte del patrimonio nobiliario con el fin de saldar las deudas del duque, quien había vivido algunos años exiliado en París. Según recuerda el hijo del librero Pedro Vindel (†1921), este empezó a negociar con la duquesa de Frías y con la condesa de Fuensalida la adquisición de parte de la rica biblioteca familiar (Cid Noé, 1945). El librero vendió la biblioteca ducal tres años después, adquiriendo el bibliófilo Francisco de Zabálburu un importante lote de entre los seis mil volúmenes que Vindel tenía en su librería, gracias a una conocida estratagema de Sancho Rayón, su bibliotecario ${ }^{13}$. Al mismo tiempo el librero negoció con el heredero de la otra rama familiar, Francisco de Borja Téllez-Girón y Fernández de Velasco (1839-1897), hijo de la citada Bernardina, duquesa de Escalona, la adquisición de su biblioteca ${ }^{14}$. Por último, Vindel afirma que también compró otro lote en 1908 a la duquesa de Frías por 6.000 pesetas, pero debió de tratarse solo de libros (Cid Noé, 1945).

No creemos que el afamado librero se conformara con la compra de la biblioteca ducal: diplomas y bulas de su archivo también estuvieron entre sus intereses. Como es sabido, varias bulas incunables, expedidas también a nombre de Leonor de Zúñiga y de la Condesa de Oropesa, fueron adquiridas por Ludwig Rosenthal a Vindel, a saber: la Bula de Guinea (c. 1477-1478) $)^{15}$, la Bula para la catedral de Ávila (1481) ${ }^{16}$ y la Bula para la Guerra de Granada (c. $1484)^{17}$. La coincidencia con respecto a las bulas coleccionadas por el conde de Valencia de Don Juan, todas a nombre de la citada Leonor, sugiere que fueron adquiridas en el mismo lugar. Rosenthal compró las suyas en Madrid durante uno de sus viajes por el sur de Europa para adquirir libros y documentos antiguos, fruto de los cuales fue la publicación entre 1907 y 1914, de catálogos para la venta de obras sobre bibliografía e historia españolas, así como también de incunables ibéricos ${ }^{18}$. El dato preciso que nos fecha la salida a la venta de sus bulas está en que James P. R. Lyell compró en 1889 a Rosenthal la citada Bula de Guinea, solo un año después de la muerte del duque de Frías, y que también le adquirió al librero muniqués las de Ávila y Granada antes de 1926, fecha de la obra del incunabulista, Early Book Illustration in Spain, donde afirma:

"Recientemente he adquirido otro ejemplar de esta Bula, también impresa sobre pergamino, pero con variantes que hasta la fecha no se han señalado” (Lyell, 1997, p. 53).

Según se deduce de estos datos, Vindel debió de vender entre 1889 y 1893 el lote de documentos relacionados con los condes de Oropesa y los duques de Frías a diferentes compradores. Lo atestigua el testimonio del librero y el hecho de que en 1899 se publicara en Madrid un catálogo impreso del archivo de la Casa de Frías (Índice general, 1899), donde dichos documentos no aparecen. Si bien no es un trabajo detallado, sorprende que su autor, que describe numerosos privilegios rodados y cédulas reales de Juan II y Enrique IV de Castilla en poder de la familia ducal, omita toda referencia a los documentos de esta misma índole que encontramos después en poder de los condes de Valencia de Don Juan. Es más, las bulas no fueron ajenas al interés de este catálogo del archivo de Frías, como demuestra la cita expresa a una caja que contenía papeles sobre la Guerra de Granada, de una bula de Cruzada concedida por el papa Sixto IV para esta guerra, en 1480. "Sin día ni mes", advierte su autor, un documento que se encuentra actualmente en el archivo sito en el $\mathrm{AHN}^{19}$. Como también estaba entonces en el archivo ducal una carta del mismo papa a Juan Pacheco en recomendación de fray Alfonso de Bolaños (24 junio 1472) $)^{20}$, nuncio papal para la venta de bulas en los reinos de España, la explicación más plausible es que en 1899 las bulas y privilegios (hoy en el Envío 127) ya no se encontraban en el archivo nobiliario de los duques de Frías, y que las que Vindel lograra adquirir provinieran de la sección "Varios", descrita en 1899 como una sección miscelánea del archivo ducal. Destaca el contenido de la numerada como 47: "Documentos eclesiásticos, Bulas y Breves de diversos Pontífices y otras dignidades de la Iglesia. La mayor parte son relativos á concesiones y dispensas otorgadas por la Santa Sede á miembros de las casas de Velasco, Pacheco y agregadas. Consta este grupo de 55 documentos"21. 
Que el archivo de los duques era por entonces muy rico en bulas se puede comprobar en la documentación que llegó a la Sección Nobleza del AHN, donde podemos hallar casi medio centenar de bulas impresas. A fines del xix, Vindel solo adquirió una parte, bien porque aquellas piezas estaban ya dispersas, bien porque solo le interesaron las bulas más antiguas y relevantes, con mejor salida comercial. El anticuario Rosenthal fue uno de los primeros compradores, llevándose las tres bulas impresas que Haebler y Lyell citarían después en sus estudios. En cambio, Juan Crooke, de formación más medievalista, debió de ser el comprador del lote hoy conservado en el Envío 127 del Instituto Valencia de Don Juan, en el que entre privilegios otorgados a los condes de Oropesa y a los Condestables de Castilla, estaban las ya citadas bulas.

Como es sabido, esto, y el hecho de que el propio Crooke falleciera poco después (el 2 de mayo de 1904), explicarían el desconocimiento que su yerno y Paz tenían sobre el origen de aquellas bulas. Tampoco tuvieron tiempo para resolver sus dudas, pues Guillermo de Osma murió el 2 de febrero de 1922 y un año después Paz cayó muy enfermo, quedando postrado en su domicilio, donde el duque de Alba, en su necrológica, recuerda que le visitaba $\left(\right.$ Alba, 1927) ${ }^{22}$. Osma, que no era bibliógrafo, no parece que se interesara demasiado por las bulas, pero sorprende que Paz (fallecido en enero de 1927) no comunicara nada al respecto. Como bibliotecario de la Biblioteca Nacional la cuestión de los incunables y de las bulas impresas no le era ajena. Al contrario, durante años había sido uno de los más asiduos corresponsales de Konrad Haebler (1857-1946) en la búsqueda de incunables españoles, y especialmente, de bulas. De algunas, conservadas en las bibliotecas de los duques de Alba, en el AHN o en el Archivo General de Simancas, Haebler le había pedido datos, calcos o reproducciones fotográficas en los años anteriores ${ }^{23}$. Y cuando en 1915 Paz publicó su catálogo de la documentación de la Casa de Medinaceli no olvidó destacar la presencia de una bula incunable en catalán, con reproducción incluida, por la que Haebler ya se había interesado años atrás (Paz y Mélia, 1915 y 1922: lámina 15-A).

Se comprende, por tanto, que cuando Paz halló en 1913 varias bulas incunables en el archivo del conde de Valencia de Don Juan fuera consciente de su importancia, destacando su presencia en el Inventario topográfico: «Por las circunstancias siguientes son curiosas 4 Bulas, dos a favor de $\mathrm{D}^{\mathrm{a}}$ Leonor de Zúñiga, y dos a favor de la Condesa de Oropesa...». Sin embargo, no proporcionó reseña alguna. En la primera papeleta dedicada a "Impresos" Paz anotó que el contenido de este catálogo bibliográfico se iniciaba en 1480 y terminaba en 1813. El bibliotecario se refería con la primera fecha a la bula del Envío 127. Tiempo después, la cita a un impreso incunable de dicho año llamó la atención de un anónimo anotador, quien intrigado por la existencia de incunables en la biblioteca anotó con un significativo círculo dicho año de 1480, y escribió: “¿Cuál hay? Ojo”, y debajo "No están fichadas”. Señalaba así que en el fichero no estaban las papeletas de aquellos impresos de 1480, error que él mismo subsanaría después, tachando el "No" y escribiendo encima "Ahora" (están fichadas), y añadiendo en una esquina que las tres bulas impresas entre $1480 \mathrm{y}$ 1490 se encontraban en el Envío ya conocido, numeradas como 11, 12 y 13: "Hay tres, Env. 127, nos. 11, 12 y 13",24. Así pues, parece que no pudieron dar a conocer la existencia de estas bulas incunables, silencio al que contribuyeron no poco las razones citadas, el carácter singular y el pequeño tamaño de las bulas, además de la clara orientación arabista y artística del Instituto desde sus orígenes.

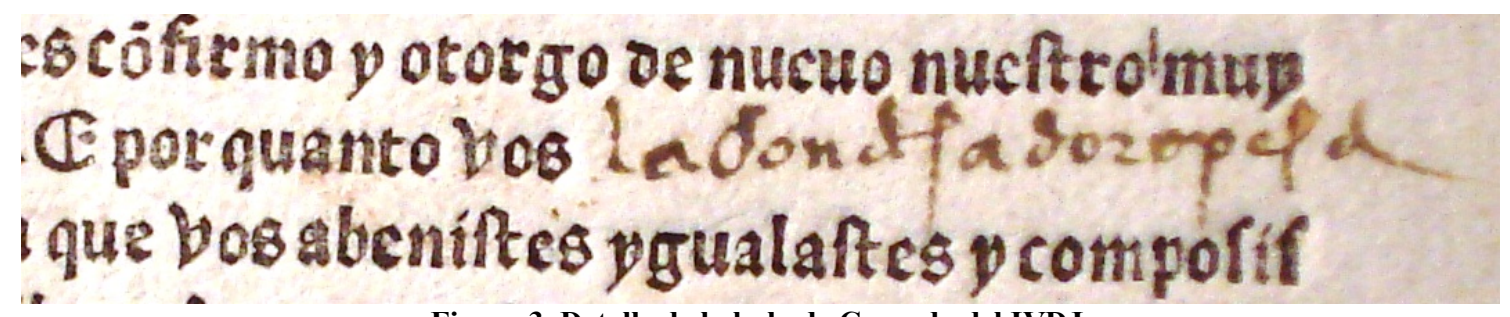

Figura 3. Detalle de la bula de Cruzada del IVDJ.

Con respecto a la identificación de la condesa de Oropesa, que adquirió esta bula, y una tercera, postincunable (1503), para el Hospital de Santiago, debemos decir que no se trata de Leonor de Zúñiga, a quien las fuentes identifican habitualmente con la condesa de Oropesa. Haebler (1903) dio pie a esta identificación cuando incluyó la Bula de Guinea (111[6]) y la de "Indulgencias de Ávila" (111[2]) en sus repertorios. Poco después Lyell (1997, p. 53) se limitó a decir que la Bula para la Guerra de Granada (c. 1484), que era de su propiedad, había sido comprada por la "Condesa de Oropesa, miembro de una familia muy conocida entre la nobleza española y de la que el primer Conde, designado unos veinte años antes de la fecha de esta bula, fue Fernando Álvarez de Toledo". En los tratados y crónicas genealógicas del siglo xvii (como en la Monarquía Española, Blasón de su Nobleza) se afirma que los primeros Condes de Oropesa fueron Fernán Álvarez de Toledo y Leonor de Zúñiga, su segunda esposa (Rivarola y Pineda, 1736, p. 46), e incluso en la Real Academia de la Historia hay un árbol genealógico de Salazar que así lo recoge ${ }^{25}$, razón por la que en el MEI (Owners of Incunabula (MEI) - CERL), se indica que el ejemplar de la Bula para la iglesia 
de San Salvador de Ávila, hoy en la Bodleian, fue comprado por "doña Leonora de Çuñiga, condesa de Oropesa, esposa de Fernán Álvarez de Toledo, primer conde de Oropesa" ${ }^{\text {26 }}$. Sin embargo, cuando se consulta la bibliografía actual (Franco Silva, 1985, 1989 y 2010), no hay duda de que el primer conde de Oropesa fue su hijo Fernando. No ha de sorprender pues, como ya se ha dicho, su padre murió en 1462, y consta que la elevación del señorío de Oropesa a título condal fue mucho después.

Leonor de Zúñiga, en consecuencia, nunca fue condesa de Oropesa, solo señora de dicho lugar. Cuando en 1470 el papa le concede el privilegio para tener un oratorio privado, se refiere a ella como viuda de Fernando Álvarez de Toledo, "señor de Oropesa"27; y en 1473 podemos comprobar cómo en el ejemplar de la Bula borjiana manuscrita conservada en el Instituto, se indica: "doña Leonor de Çuñiga señora de oropesa". Si doña Leonor nunca fue condesa de Oropesa, cabe entonces preguntarse quién fue entonces la tomadora de las otras bulas. Aunque en ninguna aparece nombre alguno, todo hace suponer que se trata de María Pacheco Portocarrero, su nuera, esposa de Fernando Álvarez de Toledo, primer conde de Oropesa. Este se casó dos veces, la primera en 1480, nada más alcanzar la mayoría de $\operatorname{edad}^{28}$. La esposa elegida fue Guiomar de Mendoza, hija del Conde de la Coruña, pero fallecería a los pocos meses. Como era imperioso asegurar la sucesión masculina en el nuevo condado de Oropesa, en septiembre de 1482 Fernando se casó de inmediato con María Pacheco, hija de Marqués de Villena, Juan Pacheco ${ }^{29}$. Para entonces es posible que Leonor de Zúñiga hubiera ya fallecido, de modo que en las bulas adquiridas por María Pacheco no pudo haber confusión alguna: la condesa de Oropesa que adquiría sus indulgencias era ella, la verdadera condesa consorte, y no su suegra $^{30}$.

\section{LA IDENTIFICACIÓN DE UNA NUEVA BULA DE CRUZADA}

La bula que nos ocupa está destinada a la guerra de Granada, otorgada por Sixto IV y renovada por Inocencio VIII. En $8^{\circ}$ apaisado, mide $160 \times 105 \mathrm{~mm}$, tiene 14 líneas de texto y en la parte inferior cuenta con firma y sello estampados. Se dejan espacios en blanco para el nombre del tomador, contribución económica y día, mes y año de la adquisición. Se incluyó a mano el nombre de la tomadora, la Condesa de Oropesa, pero no así ninguno del resto de datos.

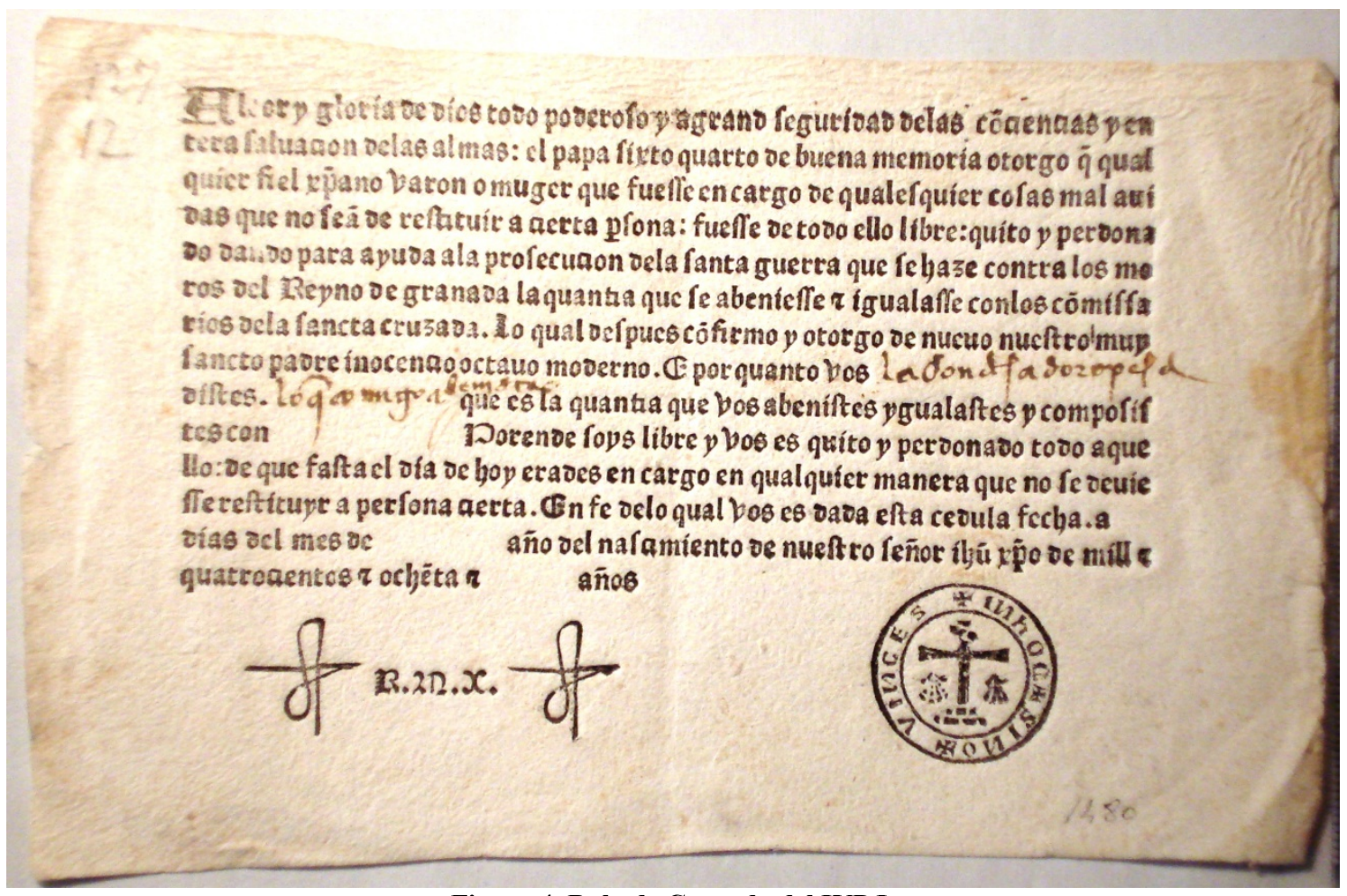

Figura 4. Bula de Cruzada del IVDJ.

El análisis de la tipografía mediante el método Proctor da una 90 G, la utilizada por el taller salmantino de Juan de Porrasen una veintena de ediciones entre 1480 y 1487-1488, según el cotejo con varias de ellas.

El taller fue fundado por Diego Sánchez de Cantalapiedra, artesano impresor de Sevilla, en sociedad por tres años con Alonso de Porras, capitalista, para la impresión de libros en Salamanca y en Sevilla. Una ejecutoria del pleito entre los 
herederos de ambos (Varona, 1994, analizada por Ruiz Fidalgo, 2006) incluye la relación de "las obras e libros que asy quedaron ynpresos e fechos antes a el tiempo que fallesçiese el dicho Diego Sánchez": quinientos sacramentales, quinientos delitorios, cuatrocientos Titulivios e diferençias. Sin embargo, estas obras, junto con los "repertorios de premáticassençiones e hordenamientosdestos reinos", están elaboradas con una tipografía distinta de la ya mencionada $90 \mathrm{G}$, pero todavía desconocida. Así, se afirma:

"Con los ynstromentos que quedaran del dicho Diego Sánchez solamente se acabaran los repertorios e para fazer las otras obras e libros e lecturas se fezieran nuevos ynstromentos".

Del primer conjunto tan solo se conocen algunas ediciones contemporáneas del Sacramental, de Clemente Sánchez de Vercial, y aunque es probable que una sea salmantina no es posible, de momento, asegurarlo fuera de la conjetura ${ }^{31}$. De "los repertorios de premáticas", se conoce la Secunda compilatiolegum et ordinationumregni Castellae, con tipografía diferente a la del resto de obras salmantinas de este taller (119 G el texto y $89 \mathrm{G}$ la glosa), pero parece que posterior a estas ediciones del primer grupo: además de citar una ley de Toledo de 1482 sobre armas en las ciudades (b7r), el título inicia con "secunda", lo que nos lleva a una edición previa que seguramente sea la citada en la ejecutoria (Ruiz García, 2011, p. 123, n. 298).

El fallecimiento de Sánchez se debió de producir hacia 1480, pues las siguientes obras que se citan en la ejecutoria se imprimen a partir de ese año: Breviario de León, sin fecha; Cuadernos de leyes de las Cortes de Toledo, 550 ejemplares, impreso después del 15 de junio de 1480; 1.800 Artes de gramática, que serían las ediciones conocidas de Nebrija: de 16 de enero 1481, de 13 de octubre de 1482 y de 5 de julio de 1483 . Después del 10 de diciembre de 1481 salieron a la luz los 300 ejemplares del Sinodal de Ávila. Por aquellas fechas se citan 450 Reglas del Obispado de León (sin ejemplar), 400 ejemplares del Breviario de Salamanca (sin ejemplar), 340 de un Libro de homilías y "sesenta y siete mil bulas, que valían cada una a maravedí". Si parte de estas obras se realizan a partir de 1480 o 1481 , las cinco elaboradas en vida de Diego Sánchez tuvieron que imprimirse al menos un par de años antes, hacia 1478 o 1479, con lo que, tal como afirma también Ruiz Fidalgo (2006, p. 960) se anticipa la introducción de la imprenta en Salamanca, aunque otra posibilidad es que los textos estén estampados en Sevilla.

La bula del IVDJ parece ser una de las 67.000 elaboradas por el taller, la primera que sale a la luz pese a la abultada tirada. Su fecha viene delimitada por la promulgación y confirmación de la bula. Sixto IV otorgó la Cruzada el 10 de agosto de 1482, que a España llega el 8 de marzo de 1483; tras su muerte, el 12 de agosto de 1484, se suspendió la bula, renovada por Inocencio VIII "moderno" el 29 de enero de 1485 (Goñi, 1958, p. 668-669). Sin embargo, los reyes no aceptaron la revalidación por la tercia que se reservaba el Papa y por los colectores, que debían ser el deán de Toledo y el prior del Monasterio de Prado. La toma de Ronda el 22 de mayo hizo cambiar la opinión del Papa, que el 26 de agosto revalida la cruzada sin la tercia (Goñi, 1958, p. 676-680), con la confirmación de los colectores solicitados y con la prórroga de un año a partir de la predicación en cada localidad.

Así pues, nuestra bula fue impresa después del 29 de agosto de 1485 y antes de la fecha de la ejecutoria en que se la cita, de mayo de 1487, siendo lo más probable en 1486. La bula más temprana conocida de esta predicación es la toledana de Juan Vázquez, tomada por Constanza Fernández el 21 de noviembre de 1485, mientras que de 1486 hay otras, también toledanas, de Vázquez y de Álvaro de Castro.

La impresión de bulas de Cruzada en Salamanca en estas fechas abre otra incógnita, dado que se suele afirmar que todas se hicieron en Toledo:

"Con la única excepción de las indulgencias de 1489, que hemos atribuido a Pedro Brun y Juan Gentil, de Sevilla, explicable por las circunstancias que concurrieron en aquella ocasión y por el cese del obispo

Ximénez de Préxano en la comisaría de la cruzada, creemos que todos los impresores que trabajaron para la cruzada, lo hicieron en Toledo [...]" (Gonzálvez, 2013, p. 162-163).

Sin embargo, la bula salmantina añade otra "excepción”, al igual que otra impresa en catalán por Nicolau Calafat en Valldemosa, en 1488, por lo que hay que replantearse cuál fue la organización de la impresión de la bula, cuándo se concedió el privilegio al toledano monasterio de San Pedro Mártir, así como la intervención de otros talleres en dicha tarea. Como se ve, una pequeña buleta genera numerosas dudas y obliga a replantearse afirmaciones que venimos realizando como si fueran incontestables.

La descripción y transcripción de la bula, por tanto, quedarían así:

[Bula de indulgencias para la guerra de Granada]. [s.l. s.i. s.a., pero: Salamanca. Juan de Porras y Juan de Montejo. Entre 29 agosto 1485 y 5 de mayo de 1487]. 
$8^{\circ}$ apaisado.- 1 h., 160x105 mm.- 90 G. - 14 líneas.- Firma y sello impresos.

Comienza: (A)loor y gloria de dios todo poderoso y agrand seguridad delas cōciencias y en / terasaluacion delas almas: el papa sixtoquarto de buena memoria otorgo q qual / quier fiel...

Termina (línea 12): ... En fe delo qual vos es dada esta cedula fecha.a [en blanco] / dias del mes de [en blanco] año del nacimiento de nuestro señor ihūxpo de mill e / cuatrocientos e ochēta e [en blanco] años / [Rúbrica impresa] R.M.X. [Rúbrica impresa] [Sello impreso]

Madrid. Instituto Valencia de Don Juan. Envío 127. Caja 170, doc. 12. [En papel, otorgada a la Condesa de Oropesa].

(A) loor y gloria de dios todopoderoso y agrand seguridad delas co[n]ciencias y en $\mid$ terasaluacion delas almas: el papa sixtoquarto de buena memoria otorgo q qual | quier fiel x[hri]stianovaron o muger que fuesse en cargo de qualesquier cosas mal aui | das que no sea[n] de restituir a cierta $\mathrm{p}$ [er]sona: fuesse de todo ello libre: quito y perdona $\mid$ do dando para ayuda a la prosecucion dela santa guerra que se haze contra los mo | ros del Reyno de granada la quantia que se abeniesse e igualasse con los co[m]missarios dela sancta cruzada. Lo qualdespuesco[n]firmo y otorgo de nueuo nuestro sancto padre inocenciooctauo moderno. E por quanto vos [ms.: la condesa doropesa]| distes. [ms.: lo que conmigo abemdra] que es la quantia que vos abenistesygualastes y composis | tes con [en blanco]. Porendesoys libre y vos es quito y perdonado todo aque | llo: de que fasta el dia de hoy erades en cargo en qualquier manera que no se deuie | sserestituyr a persona cierta. En fe delo qual vos es dada esta cedula fecha a. [en blanco] | dias del mes de [en blanco] año del nacimiento de nuestro señor ihusxpo de mill e $\mid$ quatrocientos e oche[n]ta e [en blanco] años $\mid$ [Firma impresa en la parte izquierda: GR.M.XG. En la parte derecha, sello impreso redondo: en el centro una cruz con una venera a cada lado, y alrededor la leyenda +IN HOC SIGNO +VINCES].

\section{A VUELTAS CON LA IMPRENTA SALMANTINA: CONFLICTOS Y UN NUEVO TALLER}

Volviendo al taller salmantino, tras la muerte de Diego Sánchez continuó con el taller Alonso de Porras, aunque se encargaba de la regencia Pedro de Salaya, además de "perfilar y aderezar la letra y fazerla". Al fallecer Alonso (¿1483-1484?) se apoderaron del taller Juan de Montejo, que fue denunciado por Juan de Porras, y Salaya, que se alzó con instrumentos y letras, lo que le costó estar cincuenta días preso. Fueron años agitados, pues el 12 de diciembre de 1485 los Reyes Católicos firman un documento de seguro y amparo a favor de García López de Logroño, platero, su hijo Bernardino López, clérigo, y Martín Gutiérrez, platero, para que Juan de Porras, Juan de Montejo y los oficiales del taller, así como Diego Alfonso, suegro de Porras, Juan de la Rúa, recaudador, Gonzalo de la Rúa, clérigo, y el escribano Cristóbal Alfonso,

"los non fieran, nin maten, ninlisyan, nin prendan, nin manden ferirnin matar, ninlisyar, nin prender, ninfaserninfagan otros males, nindannos, nin desaguisados algunos en las dichas sus personas e bienes contra rason e derecho",32.

No se indica el motivo de la disputa, pero parece clara la vinculación profesional al estar implicados Porras, Montejo y los oficiales del taller, por un lado, y varios mercaderes, dos de ellos plateros, por otro. Por entonces los herederos de Sánchez pleitearon con Juan de Porras para recuperar su parte, establecida en el contrato. La ejecutoria, de 5 de mayo de 1487, condena a Juan de Porras, que recurrió y realizó "una petición con muchos agravios de las dichas sentencias, diciendo ser ningunas e de algunas contra él muy injustas e agraviadas", por lo que suplicó la absolución y no pagar las costas, siendo emplazados la mujer e hijos de Sánchez en documento de 20 de septiembre de $1488^{33}$. Finalmente, tras la demanda de los herederos de Sánchez por el valor de los enseres y "quatro talares e tornos con sus instrumentos para hazer imprimir libros de molde", de los que se habían apoderado Porras y Montejo, se produce la segunda ejecutoria, de 29 de diciembre de 1489, por la que se condena a estos a 50.000 maravedíes, más 14.072 de $\operatorname{costas}^{34}$.

A lo turbio del desarrollo de este taller se añade la existencia de otra imprenta, que obliga a replantear algunos presupuestos. Así, en el cabildo salmantino de 16 de febrero de 1487 se trata la elaboración de unos misales:

"para entender e contractar e avenir e igualar con Rodrigo de Escobar, moldero, e con sus compañeros sobre los Misales que se han de façer para este Obispado e façer con ellos las iguales e preçios e tasas que para la terminación dello convenga e llamar a los aquí presentes e concertar e asentar con ellos lo que bien visto les fuere [...] lo qualcontradixo el dicho Pedro Fernández de Toro, lugarteniente del deán" (Bécares, 2016, doc. 10). 
Sin embargo, meses después, en sesión del cabildo del 8 de agosto, se volvió a tratar la elaboración de los "Misales que se avían de faser para este Obispado" (Bécares, 2016, doc. 13), para lo cual también se habían solicitado condiciones para su impresión a Porras y Montejo. Se establecen unas cláusulas (que desconocemos) y se obliga a poner una fianza de 100.000 maravedíes por si no se cumplían. Finalmente, en cabildo de 7 de septiembre se dio poder al deán, Álvaro de Paz, y a los canónigos Maluenda, Pedro Fernández y Diego Rodríguez, para que concertaran la impresión de los misales con Montejo y Porras. No se ha conservado ningún ejemplar.

Podría pensarse que Escobar y San Vicente no estaban establecidos en Salamanca, pero ambos se documentan en la ciudad en aquellas y posteriores fechas. Así, el 11 de mayo de 1488 San Vicente realiza un contrato ante notario ${ }^{35}$ con los mercaderes Martín Gutiérrez (platero, mercader y cambiador) y Lorenzo Bertini (mercader y financiero de Siena activo en Salamanca y Valladolid). Una de las últimas noticias es una mención a unas casas fronteras "de las escuelas que tienen una tienda de libros, donde la Raçión, tiénelas en vida Elvira Ruiz, hija de Juan de San Viçente", de las cuales es fiador este, dadas en cabildo de 20 de septiembre de 1494. Escobar, librero, aparece relacionado con el cabildo con temas de bienes inmuebles en 1489, 1490 y 1495 (Bécares, 2016). También se conoce un pleito que sostiene Bertini con Escobar y Bartolomé Alemán, "familiares y allegados al dicho Estudio [de Salamanca]" por una deuda de estos con el italiano, y que se conoce por el documento de inhibición al vice-escolástico del Estudio de Salamanca, de 27 de agosto de 1493, en el que se ordena ver en el Consejo el debate planteado entre la jurisdicción real y la eclesiástica ${ }^{36}$. Escobar falleció antes del 9 de enero de 1497, fecha en que el cabildo arrienda unas casas en la Puerta del Río, vacantes por su muerte (Bécares, 2016, doc. 37).

Por tanto, ambos se mantienen activos desde finales de los ochenta y, al menos desde inicios de 1487, el primero se dedica a la impresión de libros. Su presencia arroja más dudas acerca de los posibles trabajos que pudieron realizar. Para ello hay que analizar las tipografías que se usan en Salamanca a partir de esas fechas:

- 115 R (c. 1487-1495). Cerca de 20 ediciones entre el 3 de abril de 1487, con la Catholicaimpugacion de Hernando de Talavera; y las Introductioneslatinae, de Nebrija, de 30 de septiembre de 1495 (115/116 R, 85 R). En las Flores rhetorici, de Fernando Manzanares, se emplean la $90 \mathrm{G}$ y la $115 \mathrm{R}$ en la última línea, lo que parece asociar esta tipografía también a Porras y Montejo.

- 119 G / 89 G (notas) (1489?, 1495). Dos ediciones conocidas: Alonso Díaz de Montalvo, Secunda compilatiolegum et ordinationumregniCastellae; y ConfessionaleDefeccerunt, de Florentinus, de 10 de marzo de 1495. Por fechas y por la escasa producción podrían ser del taller de Escobar y San Vicente.

- 91/92 G y 122 G, a veces 150 G. (1490-1500). La conocida como "segunda imprenta anónima salmantina" o "impresor de la Gramática castellana de Nebrija". Unas 70 ediciones incunables que parecen comenzar con los Opuscula, de Tomás de Aquino, de 1490. Se pueden atribuir a Porras.

- 112 R / 85 R (usada en 1495) (1491-1500). Unas 30 ediciones incunables que comienzan con la obra de Nebrija, Epithalamium, de 15 de julio de 1491. Se pueden atribuir a Porras.

Existe la seguridad de dos talleres, siendo el de Porras el más estable. El hallazgo de otros impresos y de nuevos documentos, sin duda aportará más luz a estos complejos inicios de la imprenta salmantina.

\section{CONCLUSIONES}

La aparición de la bula salmantina de la renovación de la predicación de la Cruzada supone la corroboración de la actividad de un taller documentado, el de Juan de Porras y Juan de Montejo, y la confirmación de la documentación judicial, que hablaba de la impresión de nada menos que 67.000 bulas.

La buleta de Salamanca también plantea dudas sobre la fecha del privilegio de impresión de bulas de Cruzada en el monasterio toledano de San Pedro Mártir, pues hasta ahora se creía que todas se habían realizado en él a partir de los años 80 , lo que no parece ser tan exacto.

Si los comienzos del periodo incunable son inciertos, la identificación de estos impresos mínimos, como son las bulas, aún más. Se han adscrito a un taller sin contrastarlo suficientemente y, lo que es peor, los demás hemos seguido la estela sin espíritu crítico, por lo que hay que continuar revisando todos los impresos y los datos conocidos.

La mayor parte de los incunables salmantinos carece de datos, pero la documentación ha aportado información sobre dos talleres. Sin embargo, los cambios de tipografía dificultan su adscripción y exige una minuciosa revisión de cada una de las ediciones. 
Por otro lado, se han disipado las dudas sobre la procedencia de esta y otras bulas halladas en el Instituto Valencia de Don Juan tomadas por la condesa de Oropesa que, como se ha comentado, están relacionadas con otras de la casa ducal de Frías vendidas a finales del siglo xix.

\section{NOTAS}

1 Este artículo se enmarca en el proyecto I+D "Repertorio bibliográfico de incunables españoles" (FFI2016-78245-P), del Programa Estatal de Fomento de la Investigación Científica y Técnica de Excelencia, del Ministerio de Economía y Competitividad. La imprenta salmantina incunable la está investigando María Eugenia López Varea en su tesis doctoral, inscrita en la Facultad de Documentación de la Universidad Complutense de Madrid. José Luis Gonzalo Sánchez-Molero presentó una ponencia sobre la errónea identificación de Leonor de Zúñiga como condesa de Oropesa como tomadora de muchas bulas incunables, en las XVII Jornadas de la Asociación Española de Bibliografía.

2 Sobre el Instituto Valencia de Don Juan (en adelante IVDJ), Guillermo de Osma y Adela Crooke, se han publicado estudios, aunque de manera parcial: Andrés (1984), Partearroyo Lacaba (2009 y 2013). Destaca la reciente tesis doctoral de Nebreda Martín (2016).

${ }^{3}$ Escritura de fundación perpetua y particular del Instituto Valencia de Don Juan otorgada por el Excmo. Señor don Guillermo J. de Osma en Madrid a 15 de Marzo de 1916 ante D. Modesto Conde Caballero Notario... /. [Escritura de adición otorgada [por el mismo] en Madrid a 18 de Julio de 1917.- Ley de 11 de agosto de 1918 (Gaceta: 7 septiembre 1918) [eximiendo del impuesto de Derechos Reales las adquisiciones de este Instituto], en la Biblioteca de Palacio (Madrid), Pas. 853.

${ }^{4}$ Instituto Valencia de Don Juan. Memoria 1916, p. 29-30. Se encuentra en el archivo del IVDJ en la caja verde denominada Caja Generales: Del Museo V.D.J. Otro ejemplar se puede consultar en la Biblioteca de Palacio (Madrid): Instituto Valencia de Don Juan. Memoria. 1916. MadridImprenta Ibérica [S.a. 1917] p. 45. Encuadernada junto con la escritura arriba citada, Pas. 853.

5 Sobre el destino sufrido por la rica colección documental y libraria de la Casa Altamira, vid. Micheli (1914), Andrés (1986) y Bouza (1997).

${ }^{6}$ En carta fechada el 6 de noviembre, le dice Paz: «Buceando entre cerca de 7500 folios de documentos he recogido en más de 800 cuartillas y 500 papelitos perlitas de diversos tamaños y dientes que V. ha de engarzar después al trazar la biografía del secretario Vázquez». IVDJ. Caja Mateo Vázquez II, "n”. Sobre esta biografía Gonzalo Sánchez-Molero (2010).

${ }^{7}$ La ficha referida al Envío 127 en el volumen II, ff. 453-454.

${ }^{8}$ Hoy se encuentra en el IVDJ, signatura: C.5.4.

${ }^{9}$ Hoy gran parte de este archivo nobiliario, incluyendo la documentación administrativa que provenía del condado de Oropesa, se encuentra en el Archivo Histórico Nacional (AHN), adquirida en 1990 por compra del Estado. Una parte del archivo de los duques de Frías, propiedad de los herederos de doña María de Silva y Azlor, permanece en el Castillo de Montemayor.

${ }^{10}$ Título de Condestable concedido a Iñigo Fernández de Velasco (21-feb-1512). AHN. Nobleza. Frías. C. 601 , D.18.

${ }^{11}$ AHN. Nobleza. Frías. C. 850, D. 5-8.

12 AHN. Nobleza. Frías. C. 1469, D. 7.

${ }^{13}$ El recibo de la adquisición de unos mil títulos procedentes de la biblioteca de los duques de Frías está firmado por Vindel el 9 de noviembre de 1893 (Llera Llorente, 2007, I, p. 62-64).

${ }^{14}$ Cartas relativas a la venta de la biblioteca del Marqués de Villena a Pedro Vindel (10 marzo 1888 y 8 noviembre 1893). AHN. Nobleza. Frías. C. 1469, D. 10 .

15 ISTC: ia00459800. Tras Lyell pasó a Harry Wohlmuth, hasta que fue finalmente adquirida por la Biblioteca Nacional de España, signatura I2710(10).

16 ISTC: ia00459900. El único ejemplar conocido, que perteneció a Francisco Vindel, más tarde a Rosenthal, y a James Lyell. Se compró a Albrecht Rosenthal en 1947 por sesenta y cinco libras. Por último, perteneció a Albert Ehrman (1890-1969). John Ehrman donó finalmente la bula, en 1978, a la Bodleian Library de Oxford, signatura Broxb.95.6.

${ }^{17}$ ISTC: is00570500.

18 Sobre los catálogos de la librería de Rosentahl, vid. Löffelmeier (2002), con un anexo titulado: Katalogeund Listen des Antiquariats Ludwig Rosenthal (1864-1937). Sobre las ventas de documentos españoles realizadas por Rosenthal, vid. Mersiowsky (2005).

${ }^{19}$ AHN. Nobleza. Frías. C. 19, D. Bula de cruzada concedida por el Papa Sixto IV para la guerra de Granada, por la que se otorga facultad de perdón de los pecados reservados a la Santa Sede, a los arzobispos y obispos, hacia los fieles que concurran a la guerra de Granada o contribuyan con sus limosnas. 8. No solo carece de mes y día, como se decía en 1899, sino que es descrita casi con las mismas palabras que aquel catálogo decimonónico: " $n^{\circ} 4-1480$ (sin día ni mes). - Bula de Cruzada, concedida por el Papa Sixto IV para la guerra de Granada, en la que se otorga el perdón de los pecados reservados a la Santa Sede, los Arzobispos y Obispos, á todos los que concurrieren a dicha o contribuyan con sus limosnas" (Índice general, 1899, p. 28-29).

20 Índice general (1899, p. 89, n. 25). AHN. Nobleza. Frías, C. 113, D.1 (24 junio 1472): "Breve de Sixto IV por el que recomienda a Alfonso de Bolaño, al marqués de Villena", Tiene un regesto posterior, lo que explica la similitud entre las catalogaciones de 1899 y la actual. Resulta de interés que este se fechara cinco días antes de la publicación de la bula Pastorisaeterni (29 de junio de 1472), que concedía amplios privilegios a Bolaños en la predicación de la "bula de Guinea" (Wohlmuth, 1992, p. 521). No cita este breve a Pacheco.

${ }^{21}$ Índice general (1899, p. 6). El catálogo de dichas bulas y breves en p. 87-90.

${ }^{22}$ A su muerte en 1927, el IVDJ compró parte de su biblioteca profesional: "Libro de Adquisiciones entre 1922 y 1936. Anejos". Relación de las obras propiedad de don Antonio Paz y Mélia, adquirido a sus herederos por el Instituto Valencia de Don Juan" (26 de febrero de 1927).

23 Estudia y transcribe el epistolario López de Toro (1958). Publica 13 cartas y 3 tarjetas escritas entre 1890 y 1907 por el hispanista alemán a Antonio Paz y Mélia, conservadas en la Biblioteca Nacional de España. Por ejemplo, en 1898 escribe el incunabulista alemán a Paz: "Cuando estaba en Madrid me decía Vd. que había en la Biblioteca Nacional algunas bulas antiguas impresas, pero estaban entonces entre las manos de los ocupados en la catalogación, y por eso no pude verlas. ¿sería pedirle á Vd. demasiado, si le rogaba de hacer enviarme una lista muy ligera de las expedidas antes de 1500 ? Si añadiese a ésta algunas indicaciones sobre la bula que tiene la Exma. Señora Duquesa [de Alba] me haría un favor muy señalado". Konrad Haebler a Antonio Paz y Mélia (Dresden, 20 de abril de 1898) (López de Toro, 1958, p. 302).

24 IVDJ. Fichero 7, papeletas de Impresos. 
${ }^{25}$ Real Academia de la Historia. Salazar, D-21, fol. 65. № 22.289. Vargas Zúñiga (1955, p. 169).

${ }^{26}$ Owners of Incunabula (MEI) - CERL < http://data.cerl.org/owners/00015137>. [Consulta: 17 de agosto de 2016].

${ }^{27}$ No obstante, el cronista indiano también yerra al decir que el padre del conde fue García Álvarez, señor de Oropesa, cortesano muy querido de Juan II, y que el mayor de sus hijos "tomó título de conde en tiempo del Rey e con mucho favor" (p. 283). El condado de Oropesa, sin embargo, fue creado en 1477 por los Reyes Católicos y no por Juan II.

28 AHN. Nobleza. Oropesa. CP. 374, D. 1. Privilegio de Paulo II citado en nota anterior.

${ }^{29}$ Archivo General de Simancas (AGS). Registro General del Sello. Leg. 148011,11. 1480-11-6 Medina del Campo. Facultad para hipotecar ciertos bienes del mayorazgo de Fernando Álvarez de Toledo, conde de Oropesa, a la seguridad de la dote y arras de su esposa D. ${ }^{a}$ Guiomar de Mendoza, hija del Conde de Coruña. -Reina.

${ }^{30}$ AHN. Nobleza. Frías. C. 673, D. 6. Las capitulaciones para el matrimonio de María Pacheco con Fernán Álvarez de Toledo, conde de Oropesa, están firmadas en septiembre de 1482 .

${ }^{31}$ Una de las ediciones es la del ejemplar de la Fundación Lázaro Galdiano, mientras que de las otras dos, atribuidas sin fundamento a Burgos, Fadrique de Basilea, ¿1475?, hay ejemplares en la Biblioteca Nacional de España (Martín Abad, 2010 , S-31 y S-32 -de este último además en El Escorial-). Sobre esta obra puede verse el trabajo de López Vidriero (1988).

32 AGS. Registro General del Sello. Leg. 148512, 35.

33 AGS. Registro General del Sello. Leg. 148809, 45.

34 Real Chancillería de Valladolid. Registro de Ejecutorias. Caja 26, 51 (descrito por Varona).

35 AGS. Pergaminos. Carpeta 13,1.

36 AGS. Registro General del Sello. Leg. 149308, 248. Bartolomé Alemán era un mercader "de libros de molde" a cuya compañía se concedió exención de alcabalas para introducir libros el 22 de marzo de 1489 (AGS. Registro General del Sello. Leg. 148903, 190).

\section{BIBLIOGRAFÍA}

ALBA, JACOBO FITZ-JAMES STUART Y FALCÓ, Duque de. Necrología de don Antonio Paz y Mélia”. Boletín de la Real Academia de la Historia. 1927, tomo 90, p. 249-259.

ANDRÉS MARTÍNEZ, G. de. La fundación del Instituto y Museo Valencia de Don Juan. Madrid: Ayuntamiento de Madrid, Delegación de Cultura, Instituto de Estudios Madrileños, 1984.

ANDRÉS MARTÍNEZ, G. de. La dispersión de la valiosa colección bibliográfica y documental de la Casa de Altamira, Hispania, 1986, XLVI, p. 587-635.

BÉCARES BOTAS, V. Los agentes del libro incunable salmantino (1483-1510). Titivillus. 2016, n. 2, p. 81-105.

BOSCÁ GODINA, J. V.; MANDINGORRA LLAVATA, M. L. Hallazgo de una bula incunable desconocida en la catedral de Valencia. Contribución a la imprenta de Antonio Téllez (Toledo, 1495). Scripta. Revista Internacional de Literatura Medieval i Moderna, junio 2015, n. 5, p. 93-104.

BOUZA ÁLVAREZ, F. J. Guardar papeles -y quemarlos- en tiempos de Felipe II. La documentación de Juan de Zúñiga (un capítulo para la historia del Fondo Altamira). Reales Sitios. 1997, 131 p. 19-33.

CID NOE, P. [Seudónimo de Francisco Vindel]. Pedro Vindel: historia de una. librería, (1865-1921). Madrid: Góngora, 1945.

CROOKE Y NAVARROT, J. Catálogo histórico-descriptivo de la Real Armería de Madrid por el Conde Vdo. de Valencia de Don Juan, Madrid: Sucesores de Rivadeneyra, 1898.

FERNÁNDEZ DE OVIEDO, G. Batallas y Quinquagenas. Madrid: Real Academia de la Historia, 1983, vol. I.

FLORIT, J. M. Recuerdo de la tertulia dominguera del conde de Valencia de Don Juan. Arqueólogos, Anticuarios y Bibliófilos más o menos chiflados. Madrid, 1896-1904.

FLORIT. J. M. Recuerdo de la tertulia dominguera del Excmo. Sr. D. Alejandro Pidal: años 1904 - 1913. Madrid: [s.n.], 1919. (Fototipia Hauser y Menet).

FRANCO SILVA, A. Armas y pertrechos militares de seis fortalezas señoriales al término de la Edad Media: Oropesa, Jarandilla de la Vera, Cabañas, Villalba, Mejorada y Castilnovo. En la España medieval. 2009, n. 32, p. 193-208.

FRANCO SILVA, A. El condado de Oropesa y otros estudios de historia medieval. Jaén: Universidad de Jaén, 2010.

FRANCO SILVA, A. Oropesa. El nacimiento de un señorío Toledano a fines del siglo XIV. Anuario de Estudios Medievales, 1985 , n. 15, p. 299-314.

GARCÍA PINACHO, M. del P. (dir.). Los Álvarez de Toledo. Nobleza viva. Valladolid: Junta de Castilla y León. Consejería de Educación y Cultura, 1998.

GÓMEZ DÍAZ, R. Don Antonio Paz y Meliá (1842-1927): un archivero-bibliotecario en la Corte. Cuaderna: revista de estudios humanísticos de Talavera y su antigua tierra, 2001-02, n. 9-10, p. 177-181.

GONZALO SÁNCHEZ-MOLERO, J. L. La Epistola a Mateo Vázquez. Historia de una polémica literaria en torno a Cervantes. Alcalá de Henares: Centro de Estudios Cervantinos, 2010.

GONZÁLVEZ RUIZ, R. Las bulas de la catedral de Toledo y la imprenta incunable castellana. En Estudios sobre la imprenta incunable toledana. Toledo: Cabildo Primado Catedral de Toledo, 2013, p. 27-192.

GOÑI GAZTAMBIDE, J. Historia de la bula de la Cruzada en España. Vitoria: Editorial del Seminario, 1958.

HAEBLER, K. Bibliografía ibérica del siglo xv. La Haya, etc.: MartinusNijhoff, etc., 1903-1917. 2 v. [Ed. facsímil en Madrid: Julio Ollero, 1992]. 
HAEBLER, K. Geschichte des spanischenFrühdruckes in Stammbäumen, Leipzig: Karl W. Hiersemann, 1923.

Incunabula. Incunabula Short Title Catalogue (ISTC) (disponible en http://www.bl.uk/catalogues/istc/). [Consultado: 17 de agosto de 2016].

HAZAÑAS Y LA RÚA, J. La imprenta en Sevilla. Sevilla: Imp. de la Revista de los Tribunales, 1892.

Índice general y catálogos parciales de los documentos que existen en el Archivo histórico de la Casa de Frías. Madrid: José Góngora Álvarez, 1899.

LEÓN TELlo, P.; PEÑA MARAZUELA, M. T. de la. Catálogo de Frías, Madrid: Dirección General de Archivos y Bibliotecas y Casa de los Duques de Frías, 1955-1973. 3 vols.

LleRA Llorente, M. T. La Biblioteca Francisco de Zabálburu. Adquisición de fondos y estudio catalográfico. Mérida: Editora Regional de Extremadura, 2007, 2 vols.

LÖFFELMEIER, A. Ludwig Rosenthal als 'Wegbereiter' (1840-1928), Die Rosenthals. Der AufstiegeinerjüdischenAntiquarsfamiliezuWeltruhm, 2002.

LÓPEZ DE TORO, J. ConradHaebler y Paz y Melia. Revista de Archivos, Bibliotecas y Museos, 1958, n. LXV, p. 291-310.

LÓPEZ-VIDRIERO, M. L. La edición incunable del Sacramental de Sánchez Vercial. En El Libro Antiguo Español: Actas del primer Coloquio Internacional (Madrid, 18 al 20 de diciembre de 1986). Salamanca, etc.: Universidad, etc., 1988, p. 259-272.

LYELL, J. P. R. La ilustración del libro antiguo en España. Madrid: Ollero y Ramos, 1997.

MARTÍN ABAD, J. La primera imprenta anónima salmantina. Calligraphia et tipographia. Arithmetica et numerica. Chronologia. Barcelona: Universitat, 1998, p. 437-458.

MARTÍN ABAD, J. Catálogo bibliográfico de la colección de incunables de la Biblioteca Nacional de España.Madrid: Biblioteca Nacional, 2010.

MERSIOWSKY, M. Documentscatalans a col-leccionsparticulars. Originalsdelssegles X i XI de SantLlorenç del Munt i SantLlorençpropBagà que posseí Joaquim Areny de Plandolit. Faventia, 2005, n. 27/2, p. 57-81.

MICHELI, L. Inventaire de la CollectionÉdouardFavre (archives de la maisond'Altamira). Burdeos, 1914.

NEBREDA MARTÍN, L. Documentación sobre arte y arqueología en el Instituto Valencia de Don Juan. Análisis de la colección andalusí a través de sus documentos. Universidad Complutense de Madrid, Facultad de Ciencias de la Documentación (2016). Tesis doctoral dirigida por Juan Miguel Sánchez Vigil y Fátima Martín Escudero.

Owners of Incunabula (MEI)-CERLhttp://data.cerl.org/owners/00015137 [Consultado: 17 de agosto de 2016].

PARTEARROYO LACABA, C. Mecenazgo en una Casa-museo de coleccionista. El Instituto Valencia de Don Juan. En REYES, F. Museos y mecenazgo: Nuevas aportaciones. [s.1.]: 2009. p. 115-133.

PARTEARROYO LACABA, C. El Instituto Valencia de Don Juan: Don Guillermo de Osma y la condesa de Valencia de Don Juan. En Casas museo: museología y gestión: Actas de los congresos sobre casas museo (2006, 2007, 2008). Madrid: Ministerio de Educación, Cultura y Deporte, 2013, p. 44-59.

PAZ Y MÉLIA, A. Serie de los más importantes documentos del archivo y biblioteca del exmo. Señor Duque de Medinaceli. Elegidos por su encargo y publicados a sus expensas por Antonio Paz y Melia. I ${ }^{a}$ serie historica. II ${ }^{a}$ serie bibliográfica Años 860 - 1814. Madrid: Imprenta Alemana, 1915 y 1922.

REYES GÓMEZ, F. de los. Las Bulas de Rodrigo de Borja y los orígenes de la imprenta española. Pecia Complutense. Febrero 2008, n. 8 [en línea]. Disponible en: http://www.ucm.es/BUCM/foa/pecia/num8/Articulos/0805.htm [Consultado: 16 de agosto de 2016].

REYES GÓMEZ, F. de los. Las bulas de indulgencias incunables para la catedral de Segovia halladas en Cuéllar. Segovia Histórica. 2014, n. 1, p. 211-227.

REYES GÓMEZ, F. de los; VILCHES CRESPO, S.Del Sinodal de Aguilafuente $a$ El Adelantado de Segovia. Cinco siglos de imprenta segoviana (1472-1910). Madrid: Calambur, 2015.

REYES GÓMEZ, F. de los. Un temprano incunable sevillano (1478): Carta de jubileo a favor de la catedral de El Burgo de Osma. Titivillus. 2016, n. 2, p. 107-126.

RIVAROLA Y PINEDA, J. F. F. de. Segunda parte de la Monarquía Española, Blasón de su Nobleza. Madrid: Imprenta de Alfonso de Mora, 1736.

RUIZ FIDALGO, L. La imprenta y los libreros salmantinos en sus Siglos de Oro. En Historia de la Universidad de Salamanca. Vol. 3, Tomo 2, Saberes y confluencias, coord. por Luis Enrique Rodríguez San Pedro Bezares, Salamanca: Ediciones Universidad de Salamanca, 2006, p. 955-973.

RUIZ GARCÍA, E. La balanza y la corona. La simbólica del poder y los impresos jurídicos castellanos (1480-1520). Madrid: Ollero y Ramos, 2011.

VARGAS-ZÚÑIGA, A. de, Marqués de Siete Iglesias. Títulos y grandezas del reino, Hidalguía, 1955, 3, p. 161-176.

VARONA GARCÍA, M. A. Identificación de la primera imprenta anónima salmantina. Investigaciones históricas. 1994 , n. 14 , p. $25-33$ 
WOHLMUTH, H. Las más tempranas bulas de indulgencias españolas impresas: nuevos datos sobre la fecha de impresión de la Bula de Guinea y de la introducción de la imprenta en Sevilla. En El libro antiguo español. Actas del segundo Coloquio Internacional (Madrid), Salamanca, etc.: Universidad, etc., 1992, p. 493-553. 